\title{
Work related upper limb disorder: the relationship between pain, cumulative load, disability, and psychological factors
}

\author{
P S Helliwell, D B Mumford, J E Smeathers, V Wright
}

\begin{abstract}
Repetitive strain injury, or work related upper limb disorder, provides an interesting paradigm for the study of the relative contribution of physical and psychological factors to the resulting pain and disability. Sixty three subjects were studied, comprising the workforce of a subsection of a large local industrial company, in whom pain in the arm related to work was known to be common. Ergonomic data were obtained by estimating the cumulative daily load on the wrist joint for each of four identified tasks. Data on the occurrence of pain, treatment sought, and disability were obtained by a structured self administered questionnaire. Psychological data were obtained by administering the Hospital Anxiety and Depression (HAD) scale, a self reported measure of anxiety and depression, and the Bradford Somatic Inventory (BSI), an inventory of somatic symptoms associated with anxiety and depression. The employment specific period prevalence of work related upper limb disorder was $81 \%$, with $30 \%$ of the subjects having pain at the time of the study. Domestic disability was minimal in all but two subjects, though the use of devices such as jar openers at home was common (12 of 51 subjects). Medical advice was seldom sought. Twenty per cent of subjects had received antiinflammatory drugs, $10 \%$ had received physiotherapy, and $47 \%$ had wrist splints. Pain was related to the tasks with the highest estimated daily loads, but a history of pain and current pain were associated with higher scores on the HAD and BSI scales, suggesting an interaction between physical and psychological factors.
\end{abstract}

Rheumatology and

(Ann Rheum Dis 1992; 51: 1325-1329)

Rehabilitation Research

Unit, Department of Clinical Medicine, University of Leeds, Leeds, United Kingdom P S Helliwell

J E Smeathers

$\mathrm{V}$ Wright

Academic Unit of

Psychiatry,

Department of

Clinical Medicine,

University of Leeds,

Leeds, United Kingdom

D B Mumford

Correspondence to:

Dr P S Helliwell,

Rheumatology and

Rehabilitation Research Unit,

36 Clarendon Road,

36 Clarendon Road,

Leeds LS2 9NZ,

United Kingdom.

Accepted for publication

17 July 1992
Pain in the arm related to work is increasingly recognised as an occupational disorder which may cause significant sickness absenteeism. Excessive cumulative static loading and repetitive low magnitude dynamic loading may contribute to the disorder. ${ }^{1}$ The clinical characteristics vary from recognised disorders such as carpal tunnel syndrome and stenosing tenosynovitis to a purely symptomatic illness. Opinions on the aetiology of work related upper limb disorder vary from the orthodox medical model of illness where physical factors are thought to cause tissue damage ${ }^{2}$ to an alternative viewpoint where it is ascribed to psychological factors and is seen as a sociopolitical phenomenon. ${ }^{3} \mathrm{~A}$ combined view, where physical and psychological factors interact, has been advocated by Smith et al. ${ }^{4}$ Where the disorder is recognised, and the worker liable to financial compensation, work related upper limb disorder may occur more often, though precise incidence figures from areas with different tort laws have not been reported. Changes in the law may affect disease incidence, however. ${ }^{5}$

Our help was requested by a local firm in which a high prevalence of work related upper limb disorder occurred. The affected employees all came from the same section of the factory and, as they were intending to move this section to a new site in the near future, any ergonomic recommendations we might make could be incorporated at this time. This provided us with an opportunity to study the contribution of ergonomic (and in particular estimated cumulative static and dynamic loads) and psychological factors to work related upper limb disorder in this workforce.

Our hypothesis was that excessive cumulative loads cause work related upper limb disorder but the occurrence and severity of the pain and the associated disability are modified by anxiety, depression, and a selective focus on somatic sensations.

\section{Subjects and methods}

The factory was visited on two occasions. On the first occasion video recordings were made of the major tasks and an informal survey of symptoms and work difficulties was undertaken. On the second occasion more formal medical interviews were carried out and more complete ergonomic data were obtained using a stopwatch, component weights, and dimensional measurements for each main workstation. At the second visit a structured self administered questionnaire was handed out to all the workforce in that section with instructions to answer the questions anonymously at home. All the questionnaires were returned within one week. The questionnaire consisted of three parts. Part 1 was designed specifically for this study and sought information on work history, pain history, treatment, performance at work, and non-occupational disability using questions adapted from the Stanford Health Assessment Questionnaire. ${ }^{6}$ Part 2 consisted of the Hospital Anxiety and Depression.(HAD) scale devised by Zigmond and Snaith ${ }^{7}$ as a measure of anxiety and depression in a study group in a hospital. This is a 14 question, self administered questionnaire easily completed in a few minutes. A score of 7 or less on either dimension is regarded as normal, 8-10 borderline, and over 10 abnormal. Part 3 consisted of the Bradford Somatic Inventory (BSI) scale devised by Mumford 
et $a l^{8}$ as a comprehensive inventory of somatic symptoms associated with anxiety and depression. It consists of a 44 item self administered questionnaire covering a wide range of somatic symptoms referable to a number of different anatomical sites. Factor analysis of the BSI responses of medical outpatients with no organic illness yielded four principal factors: 'head', 'chest', 'abdomen', and 'fatigue'; few of the BSI symptoms are directly related to the musculoskeletal system. Although the BSI is still undergoing full evaluation, ${ }^{8}$ a score of 20 or more (out of a maximum of 88 ) is regarded as abnormal.

\section{ERGONOMIC METHODS}

The factory produces cardboard packaging for a variety of foodstuffs. The card is printed, cut, glued, packaged, and then despatched to the various food manufacturers. This study was carried out in the section of the factory where the printed card is received in large (approximately $1 \mathrm{~m}^{2}$ ) sheets and stacked in bundles approximately $1 \mathrm{~m}$ high. Four main tasks were identified. (a) Stripping waste. To remove the waste card from the printed pre-cut sheets, about 50 sheets are lifted slightly with the left hand using a wide pinch grip while the right hand is used to hit the sheets with a mallet. This operation breaks the tabs and allows the required card to be teased out with a strong pinch grip and twisting action of the left hand. $(b)$ Sorting of the stripped card is necessary to detect any faults in the printing. Batches of card are lifted with a wide pinch grip and flicked through using the opposite thumb. This task is combined with lifting and placing the product in and out of larger boxes. (c) Feeding involves placing the printed cards into the hopper of the machine for bending and gluing. This requires the worker to lift the batch of cards with a two handed wide pinch grip, stack to ensure the edges are aligned, and then to deliver them into the feeder with the wrists extended and the forearm in a supine position. (d) Take off occurs at the other end of the machine where the finished product is lifted off and packaged into boxes using a wide pinch grip.

The repetitious nature of each of the major tasks was estimated from observations in the workplace and from the video recordings using a stopwatch and counting the number of repeated hand movements. The cycle time is the length of time taken to repeat a particular operation. The total time spent at the workstation divided by the cycle time gave an estimate of the number of repetitions per day for each task. The peak forces in the flexor tendons of the wrist were estimated using a simple geometric model of the hand and Newtonian mechanics. For pinch grips the peak force in the flexor tendons was found to be four times the weight of card lifted (assuming the coefficient of friction of card on card to be about 0.25 ). This applied mainly to 'sorting' and 'take off' tasks. For other tasks such as 'feeding' or stacking card the hand was used mainly in a supine position and the peak force in the flexor tendons was five times the moment (in Newton metres) produced by the weight of card about the wrist joint (assuming the main flexor tendons lie approximately $2 \mathrm{~cm}$ away from the centre of the radius bone). This model has not previously been validated and serves only to give an estimate of the forces involved. It should be noted that in vivo forces are likely to be much larger due to the additional effect of inertial and antagonistic muscle forces which were not included in the biomechanical model. The relative severity of each task was found by comparing the cumulative daily load on the wrist for each task. The cumulative daily load is defined as the maximum tensile force in the flexor tendons of the wrist multiplied by the number of repetitions per day, allowing for the amount of material handled by each operative. This last factor was important as certain tasks were partially automated and job rotation was allowed at some workstations.

\section{STATISTICAL METHODS}

The data were analysed using the statistical packages SPSSX-PC and Minitab. Non-parametric tests were used for comparing medians and proportions (Kruskall-Wallis, MannWhitney and $\chi^{2}$ with Yates's correction). Details of logistic regression analysis are given in the text.

\section{Results}

ERGONOMIC ASSESSMENTS

Table 1 gives, for each task, the cycle time (the time taken for a single repetition of the task), the number of repetitions per day, the estimated peak force in the flexor tendons, and the relative severity of each task based on the cumulative daily load. Although stripping waste was associated with large peak loads, recent improvements in the printing machinery have resulted in $80 \%$ of cards arriving already stripped so that

Table 1 Analysis of tasks

\begin{tabular}{|c|c|c|c|c|}
\hline Task & Cycle time(s) & Repetitions/day & $\begin{array}{l}\text { Estimated peak } \\
\text { force in flexor } \\
\text { tendons }(N)\end{array}$ & $\begin{array}{l}\text { Relative severity } \\
\text { of individual tasks } \\
\text { (based on cumulative } \\
\text { daily load (see text)) }\end{array}$ \\
\hline \multicolumn{5}{|c|}{ Stripping waste } \\
\hline Hammer & $3 \times$ every cycle & 5220 & - & - \\
\hline Twisting & $4-15$ & $1740-6525$ & 224 & $2 \cdot 8$ \\
\hline Pulling & $25-50$ & $522-1044$ & - & - \\
\hline \multicolumn{5}{|l|}{ Sorting } \\
\hline Hold & $20-30$ & $870-1305$ & 62 & $1 \cdot 0$ \\
\hline Flick & $2-3$ & $8700-13000$ & - & - \\
\hline Feeding & $10-30$ & $870-2610$ & 270 & $20 \cdot 7$ \\
\hline Take off & $5-30$ & $870-5220$ & 40 & $13 \cdot 9$ \\
\hline
\end{tabular}


only $20 \%$ of the departmental throughput is handled in this way. About $20 \%$ of the take off stations were fully automated and less than $10 \%$ of the products passed through the sorting workstation. The tasks were thus ranked relative to the task with the lowest cumulative daily load (sorting).

\section{RELATIONSHIP BETWEEN PAIN AND TASK}

Eighty five questionnaires were distributed. Sixty six were returned and of these only 63 were fit for analysis (two returned by office workers, one spoilt). All employees were women. Their age (median (range)) was 36 (18-57) years, the number of years worked in the factory was $15(1-42)$, and the years worked in the current job were five $(0 \cdot 3-32)$. For each task the number (percentage) of workers was: stripping waste, 15 (24\%); sorting, 22 (35\%), feeding, five ( $8 \%)$; and take off, seven $(11 \%)$. In addition, nine $(14 \%)$ workers performed both feeding and take off and five $(8 \%)$ rotated through all four tasks providing holiday and sickness relief. Fifty one subjects answered 'yes' to the question 'have you ever had pain in the hand, wrist, or arm related to work' thus giving a period prevalence in the respondents of $81 \%$. Nineteen $(30 \%)$ reported pain at the time of answering the questionnaire.

Table 2 compares the subjects with and without a history of pain in relation to the task performed. As individual cell frequencies were small, job categories were combined and the two tasks ranked highest in cumulative daily load (feeding and take off) were compared with the other tasks. As shown in table 2, proportionately more subjects in the high risk tasks of 'feeding' and 'take off had pain in the arm at the time of the study (10/21 in high risk tasks; $9 / 42$ in low risk tasks; $\chi^{2}=5.89$; degrees of freedom $=1 ; p<0.02$ ). The high proportion of subjects with a history of arm pain is explained by the changes to working practice outlined earlier. In general, subjects reporting pain were older (median 37 years with pain; 32.5 years without) and had worked for less time in their current job (median 4.5 years with pain; 9.5 years without). Also of interest was the number of smokers among the subjects who had experienced pain $(n=24 ; 47 \%)$ compared with the group without pain $\left(n=1(8 \%) ; \chi^{2}=5.42\right.$; $\mathrm{p}<0.025$ ).

TREATMENT, WORK PERFORMANCE, AND DOMESTIC DIFFICULTIES

In the 51 subjects with a history of work related upper limb disorder the following treatments had been tried: $24(47 \%)$ wrist splints, $10(20 \%)$ anti-inflammatory drugs, and $5(10 \%)$ physiotherapy. Fourteen $(27 \%)$ subjects had taken time off work because of pain; the longest duration of sick leave was 13 weeks with a median of 1.7 weeks. Of the subjects with a history of pain $43 \%$ said they were now able to perform all usual work duties without pain, $49 \%$ were still having pain but were able to manage at work, and $8 \%$ had changed their work because of pain.

Overall, major domestic disability was not found. Nine subjects reported difficulty dressing, 17 difficulty with grip and, in addition, three subjects reported the use of a dressing device and 12 the use of a device to help open jars or taps.

RELATION BETWEEN PAIN, PERFORMANCE, ANXIETY, DEPRESSION, AND SOMATIC SYMPTOMS Only four subjects had changed their job (within the company) because of arm pain. Twenty four subjects stated that they continued to do their present job but with persistent arm pain and 19 subjects reported pain at the time of the study.

To provide a spectrum of severity the total group was divided into three subgroups according to pain history and the results are presented in table 3. Subjects who had never experienced pain in the arm had been in their current job longer than those subjects who were currently

Table 2 History of pain by task type

\begin{tabular}{llllll}
\hline Group & $\begin{array}{l}\text { Median (range) } \\
\text { age (years) }\end{array}$ & $\begin{array}{l}\text { Median (range) } \\
\text { time in job } \\
\text { (years) }\end{array}$ & $\begin{array}{l}\text { No of subjects } \\
\text { who never } \\
\text { had pain }\end{array}$ & $\begin{array}{l}\text { No of subjects } \\
\text { with pain } \\
\text { during study }\end{array}$ & $\begin{array}{l}\text { No of subjects } \\
\text { with history } \\
\text { of pain }\end{array}$ \\
\hline $\begin{array}{l}\text { Stripping waste, sorting, } \\
\text { all four tasks (n=42) }\end{array}$ & $37(18-57)$ & $\begin{array}{l}4 \cdot 5 \\
(0 \cdot 3-32)\end{array}$ & 9 & 9 & 24 \\
Feeding, take off $(\mathrm{n}=21)$ & $35(21-55)$ & $\begin{array}{l}6 \cdot 0 \\
(0 \cdot 3-29)\end{array}$ & 3 & 10 & 8 \\
Total group (n=63) & $36(18-57)$ & $\begin{array}{l}5 \\
(0.3-32)\end{array}$ & 12 & 19 & 32 \\
\hline
\end{tabular}

Table 3 Comparison of subjects with and without a history of pain. Results are median (range) values. Groups compared using the Kruskall-Wallis test

\begin{tabular}{|c|c|c|c|c|}
\hline Group & $\begin{array}{l}\text { Never had pain } \\
(n=12)\end{array}$ & $\begin{array}{l}\text { Pain in past } \\
(n=32)\end{array}$ & $\begin{array}{l}\text { Pain now } \\
(n=19)\end{array}$ & p Value \\
\hline $\begin{array}{l}\text { Age (years) } \\
\text { Time at factory (years) } \\
\text { Time in current job (years) } \\
\text { Anxiety score } \\
\text { Depression score } \\
\text { Bradford Somatic Inventory Score } \\
\text { Number ever having taken time } \\
\text { off work due to pain }\end{array}$ & $\begin{array}{l}31 \cdot 5(23-55) \\
14.5(1 \cdot 5-39) \\
10 \cdot 5(0 \cdot 7-20) \\
2.5(0-8) \\
1.0(0-9) \\
6.5(0-17) \\
0\end{array}$ & $\begin{array}{r}32 \cdot 5(18-57) \\
12 \cdot 5(1-42) \\
8 \cdot 0(1-32) \\
5 \cdot 5(1-13) \\
3 \cdot 0(0-16) \\
13 \cdot 5(0-34) \\
4\end{array}$ & $\begin{aligned} 43 \cdot 0 & (21-54) \\
17 \cdot 0 & (4-36) \\
3 \cdot 0 & (0 \cdot 3-29) \\
7 \cdot 0 & (1-20) \\
5 \cdot 0 & (1-11) \\
17 \cdot 0 & (1-66) \\
10 & \end{aligned}$ & $\begin{array}{l}\text { NS } \\
\text { NS } \\
0.037 \\
0.004 \\
0.045 \\
0.002\end{array}$ \\
\hline
\end{tabular}

${ }^{*} \mathrm{NS}=$ not significant. 
Table 4 Logistic regression analysis. The dependent variable was pain in the arm (at any time). Goodness of fit: $\chi^{2}=52 \cdot 80$; degrees of freedom $=56 ; p=0 \cdot 60$

\begin{tabular}{lcllll}
\hline & Coefficient & Standard error & $p$ Value & Odds ratio & $\begin{array}{l}\text { 95\% Confidence } \\
\text { interval }\end{array}$ \\
\hline Anxiety & & & & 1.32 & 0.95 to 1.83 \\
Depression & 0.2799 & 0.1672 & 0.09 & 0.93 & 0.71 to 1.22 \\
BSI 44* & -0.0718 & 0.1376 & 0.60 & 1.04 & 0.97 to 1.13 \\
Task & 0.0443 & 0.0402 & 0.27 & $\mathbf{6 . 4 2}$ & 1.52 to 27.05 \\
Constant & 1.8598 & 0.7336 & 0.01 & & \\
\hline
\end{tabular}

${ }^{*} \mathrm{BSI}=$ Bradford Somatic Inventory score

experiencing pain in the arm, suggesting a higher job turnover in the latter group $(p=0.07$; Mann-Whitney). A significant increase in HAD scores for anxiety and depression, and BSI scores occurs across the groups, in line with increasing symptom severity.

To test the hypothesis that pain in the arm is a function of physical and psychological factors a logistic regression model was constructed. Table 4 presents the results. Anxiety, depression, and BSI scores were included as continuous variables; categorisation using accepted cut off points (see under Subjects and methods) markedly reduced the goodness of fit of the model. The task was coded categorically with the 'high risk' tasks of feeding and take off as 1 , other tasks as 0 . All five possible interactions were entered into the main effects model but none was significant. In this model the only significant effect was for task. An analysis of deviance (see table 5) showed the effect of anxiety to be significant in addition to task; again, none of the interactions was significant.

\section{CLINICAL FINDINGS}

As the visits were made during the working day it was not possible to take a full history and make a complete examination in all subjects reporting pain. It became clear that most subjects had been employed by the firm for many years and that the turnover of workers was extremely low. Back pain had been a problem in the past, particularly in the waste stripping section but, with the introduction of scissor lifts in this section, the problem no longer existed.

Ten subjects were examined. Carpal tunnel syndrome was apparent in five (either positive history and Phalen's test, or history of carpal tunnel decompression) and a further two subjects (not examined) were thought to have had an operation for this disorder. Advice from the factory nurse (available full time) and doctor (available once a week) had rarely been sought.

Table 5 Analysis of deviance. The dependent variable was pain in the arm (at any time)

\begin{tabular}{llccc}
\hline Factor(s) & Deviance & $\begin{array}{l}\text { Degrees of } \\
\text { freedom }\end{array}$ & $p$ Value \\
\hline Constant & 75.67 & & 60 & 0.13 \\
Task (T) & 71.72 & 3.96 & 1 & 0.047 \\
Anxiety (A) & 63.91 & 11.76 & 1 & $<0.001$ \\
Depression (D) & 71.33 & 3.93 & 1 & 0.047 \\
BSI 44(B)t & 66.16 & 9.51 & 1 & $<0.01$ \\
A+D & 63.12 & 0.79 (Dadj) & 1 & $\mathrm{NS}$ \\
A+B & 62.20 & 1.71 (Badj) & 1 & $<0.01$ \\
A+B+D+T & 54.32 & 9.59 (Tadi) & 1 & \\
\hline
\end{tabular}

NS = not significant.

†BSI = Bradford Somatic Inventory score.
The factory nurse did have a supply of leather supports. These consisted of a wide leather buckle which fastened at the distal part of the forearm and did not restrict movement at the wrist: few employees used these.

\section{Discussion}

This study was carried out in a factory where the prevalence of work related upper limb disorder was known to be high. Management and workers were keen to alleviate the problem and the impending relocation provided them with an opportunity to make any necessary ergonomic improvements. Many of the employees had been working with the firm since leaving school; the median duration of employment was 15 years. Our investigation was therefore facilitated by a well motivated and cooperative workforce reflected in the high response rate to our questionnaire $(78 \%)$. Against this advantage the numbers in the task subgroups were small, making interpretation of the results difficult.

The presence of work related upper limb disorder in this study was $81 \%$. Our hypothesis predicted that pain would occur predominantly in the group subjected to the highest daily cumulative loads and this is suggested by the results in tables 1 and 2 , and confirmed by logistic regression analysis. A tendency to change tasks as a result of work related upper limb disorder would confound these results but only four subjects reported having changed job task as a result of pain. Nevertheless, subjects currently having pain in the arm had been in their current job for a median of only three years, significantly shorter than other workers in this study.

The second part of our hypothesis predicted that the occurrence and severity of work related upper limb disorder would be associated with our estimates of anxiety, depression, and the BSI scores. Subjects reporting pain were distinguished by higher BSI, anxiety, and depression scores. The scores on the four BSI factors (head, chest, abdomen, fatigue) showed that symptoms referable to all components contributed equally to the total score. In other studies BSI has been found to distinguish subjects presenting to medical clinics with nonorganic 'functional' disorders within Britain and in Pakistan. 8 This study suggests that, whatever the mechanisms involved, subjects who express widespread somatic symptoms also report more pain attributable to their job. Scores for anxiety, depression, and BSI were, not surprisingly, highly related.

We have been unable to distinguish whether 
our subjects with pain had higher scores for psychological variables because they had pain, or whether psychological traits predisposed to the production of symptoms. No interaction between psychological variables and physica variables could be shown on logistic regression, yet the results in table 3 suggest that even when patients obtain relief from arm pain higher scores for anxiety, depression, and BSI persist. This question could be answered by a prospective study and we are embarking on such a study in relation to low back pain in industry.

Undoubtedly other factors should be considered in a model of symptom production in work related upper limb disorder. ${ }^{10}$ Studies of the occurrence of low back pain in industry have emphasised the importance of work satisfaction, stress, and other psychosocial factors in the reporting of symptoms. ${ }^{11}$ Pain in the cervical spine and upper arm in secretaries has also been related to work stress, yet the importance and possible interaction of ergonomic factors was shown. ${ }^{12}$ Some authors argue vehemently that physical factors are irrelevant, the 'functional' pain achieving importance by the incorrect application (by doctors) of the 'injury' model. ${ }^{13}$ This study supports an interrelation between physical and psychological factors. The mechanism of production of pain remains unclear but may be related to muscle fatigue ${ }^{14}$ and would be more likely to be expressed in subjects who experience emotional distress as somatic symptoms.

This study has several practical implications. Whenever work related upper limb disorder occurs, a reduction in the cumulative daily load should be made, if possible. Often this can be achieved by simple ergonomic measures without a loss of production (an essential requirement imposed on us by the firm in this study). Some workers in this study were at risk because of the way they performed a particular task, so that education before and during employment is necessary.

Among subjects who report pain, a number have evidence of emotional distress and may benefit from counselling to try to identify the causes of their distress. In this group it may be that psychological treatment will have more to offer than physical treatment. The role of physical treatment such as anti-inflammatory drugs, physiotherapy, resting splints, and steroid injections remains to be elucidated.

1 Dalton S, Hazleman B L. Repeated movements and repeated trauma. In: Raffle P A B, Lee W R, McCallum R I, Murray
R, eds. Hunter's diseases of occupations. 6th ed. London: Edward Arnold, 1987.

2 McDermot F T Repetition strain injury: a review of current understanding. Med $\mathcal{f}$ A ust 1986; 144: 196-200.

3 Ireland D C R. Psychological and physical aspects of

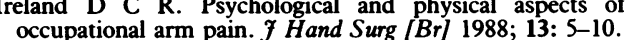
occupational arm pain. F Hand Surg [Br] 1988; 13: 5-10.
Smith M J, Cohen B G F, Stammeriohn L W. An investigation of health complaints and job stress in video display operations. Hum Factors 1981; 23: 387-400.

5 Reilly P A, Travers R, Littlejohn G O. Epidemiology of softtissue rheumatism: the influence of the law. $\mathcal{J}$ Rheumatol 1991; 18: 1448-9.

6 Kirwan J R, Reeback J S. Stanford Health Assessment Questionnaire modified to assess disability in British patients with rheumatoid arthritis. Br F Rheumatol 1986;
25: 206-9. Zigmond A S, Snaith R P. The Hospital Anxiety and Depression Scale. Acta Psychiatr Scand 1983; 67: 360-70.

Mumford D B, Bavington J T, Bhatnagar K S, Hussain Y, Mirza S, Naraghi M M. The Bradford Somatic Inventory in a multi-ethnic inventory of somatic symptoms reported by anxious and depressed patients in Britain and the IndoPakistan Subcontinent. Br f Psychiatry 1991; 158: 379-86.

9 Mumford D B, Tareem I A K, Bhatti M R, Bajwa M A Z, Ayub M, Pervaiz T. An investigation of 'functional' somatic symptoms among patients attending hospital medical clinics in Pakistan-II using somatic symptoms to identify patients with psychiatric disorders. $\mathcal{F}$ Psychosom Res 1991; 35: 245-64.

10 Helliwell P'S. Occupational rheumatology-are we using the wrong model? Br ₹ Rheumatol 1992; 31: 73-4.

11 Bigos S J, Battie M C, Spengler D M, et al. A prospective study of work perceptions and psychological factors affecting the report of back injury. Spine 1991; 16: 1-6.

12 Kamwendo K, Linton S J, Moritz U. Neck and shoulder disorders in medical secretaries. Scand f Rehabil Med 1991; 23: $127-33$.

13 Lucire Y. Neurosis in the workplace. Med $\mathcal{Y}$ Aust 1986; 145: 323-7.

14 Valencia F. Local muscle fatigue. Med $\mathcal{f}$ Aust 1986; 145: 327-30. 